\title{
Peran Self Disclosure terhadap Resiliensi pada Remaja di Panti Asuhan
}

\author{
Ester ${ }^{1}$, Diny Atrizka ${ }^{2}$, Achmad Irvan Dwi Putra ${ }^{3}$ \\ Fakultas Psikologi, Universitas Prima Indonesia ${ }^{1,2,3}$ \\ escapreli@yahoo.com ${ }^{1}$,diny.dinyrizk@gmail.com², achmadirvandwiputra@unprimdn.ac.id ${ }^{3}$
}

\begin{abstract}
Abstrak
Remaja di panti asuhan dihadapkan pada berbagai resiko dan tekanan yang berdampak pada psikologisnya. Remaja yang mengalami tekanan cukup sulit untuk mengendalikan diri dari masalah yang terjadi disebabkan karena diusia remaja yang masih tergolong labil serta suasana hati yang mudah berubah-ubah. Resiliensi harus dimiliki oleh remaja di panti asuhan agar mereka mampu bertahan dalam menghadapi kesulitan hidup. Penelitian ini bertujuan untuk mengetahui hubungan antara self disclosure dengan resiliensi. Sampel dalam penelitian ini adalah sebanyak 90 remaja (58 laki-laki dan 32 perempuan). Berdasarkan hasil penelitian yang dilakukan dengan teknik Pearson Product Moment Correlation menunjukkan koefisien korelasi sebesar 0,678 dengan $\mathrm{p}=0,000(\mathrm{p}<0,05)$ yang berati adanya hubungan yang positif dan signifikan antara self disclosure dengan resiliensi pada remaja panti asuhan.
\end{abstract}

Kata kunci: panti asuhan; remaja; resiliensi; self disclosure

\begin{abstract}
Adolescents in orphanage are faced with a variety of risk and pressure which affects to their psychological wellbeing. Depressed adolescents will be difficult to control themselves from the problems they got. Resilience must be had by the adolescents in orphanage so they are able to survive in facing adversity in life. This study aims to find relationship between self disclosure and resilience. The sample of this study were 90 adolescents (58 male and 32 female). Based on the results of research conducted with Pearson Product Moment Correlation techniques showed a correlation coefficient of 0.678 with $\mathrm{p}=0.000(\mathrm{p}<0.05)$ which means there is a positive relationship between self disclosure and resilience of adolescents in orphanage.
\end{abstract}

Keywords: orphanage; adolescents; resilience; self disclosure

\section{PENDAHULUAN}

Panti asuhan merupakan lembaga sosial yang di tujukan untuk membantu anak-anak yang sudah tidak memiliki salah satu atau kedua orang tua. Anak yang mendapatkan pengasuhan dari panti asuhan memiliki perbedaan dengan anak dari keluarga lengkap dalam mengatasi masalah, termasuk saat remaja. Irshad (2017) mengungkapkan bahwa remaja yatim piatu memiliki tingkat stres yang lebih tinggi dibanding remaja yang masih memiliki orangtua. Pada kenyataannya tidak semua anak dapat tinggal bersama dengan keluarga dan dapat merasakan cinta dan kasih sayang, terutama dari orangtuanya. Namun, tidak dapat diyakini pula bahwa mereka yang tinggal di panti mendapatkan kasih sayang dan perhatian layak Dayakisni dan Hudaniah (2009). Apelian dan Nesteruk (2017) juga mengungkapkan bahwa remaja mengalami beberapa kesulitan yang dihadapi setelah ditinggalkan orangtua seperti perubahan kegiatan harian, masalah finansial, dan tidak memiliki tempat tinggal tetap.

Kesulitan yang di hadapi oleh remaja dalam mengatasi masalah dapat di permudah 
dengan adanya resiliensi. Resiliensi merupakan sebuah keinginan yang mendasari seseorang untuk dapat bangkit dari kesulitan-kesulitan yang dialami. Menurut Pidgeon, Rowe, Stapleton, Magyar, dan Lo, (2014) resiliensi adalah term dari individu yang memungkinkan untuk membuat keadaan yang lebih menguntungkan atau layak dari sesuatu yang menyakitkan dan keras, serta memberi semangat dan memberikan sebuah hubungan.

Pada kebanyakan penelitian resiliensi di kaitkan dengan hal-hal traumatis (Desmita, 2008; Ungar, 2008). Ungar (2008) menyebutkan bahwa dalam pemulihan pasca trauma resiliensi dapat memberikan fungsi positif untuk membantu individu. Bahkan oleh pandangan kontemporer paradigm resiliensi dianggap sebagai ranah yang menggambarkan bagaimana anak, remaja maupun orang dewasa untuk sembuh dari kondisi stress, trauma maupun risiko dalam kehidupan (Desmita, 2008) .

Penelitian Nisa dan Muis (2016) justru mengungkapkan resiliensi tidak hanya terkait dengan hal traumatis, bahwa individu dengan resiliensi tinggi memiliki karakteristik tidak menyerah, berusaha untuk menghadapi masalah, percaya diri, dan memiliki keyakinan untuk menjadi orang sukses. Dengan kata lain resiliensi, yang baik dapat membantu individu di panti asuhan untuk membantu sukses dan mampu menyelesaikan masalah.

Salah satu faktor yang mempengaruhi resiliensi individu adalah self disclosure. Ko dan $\mathrm{Pu}$, (2011) menyebutkan bahwa self disclosure dapat memengaruhi tingkat resiliensi seseorang, dimana semakin tinggi self disclosure pada remaja, maka semakin tinggi resiliensi dan sebaliknya. Sehingga, self disclosure berkorelasi positif dengan resiliensi, yang berati tingginya self disclosure juga berdampak pada tingginya resiliensi seseorang.

Omarzu (2000) mengajukan Disclosure Decision Model (DDM) dan menyatakan bahwa self disclosure adalah sebuah proses kognitif dalam pengambilan keputusan. Proses dapat melibatkan variabel-variabel yang ada dalam proses pengambilan keputusan untuk membuka diri atau tidak, meskipun situasinya berbeda-beda. Disclosure Decision Model (DDM) menjelaskan proses kognitif pengambilan keputusan yang mempengaruhi isi, kedalaman, keluasan, dan durasi keterbukaan diri seseorang. Salah satu atau lebih dari lima fungsi dasar atau tujuan keterbukaan diri harus dapat diakses. Self disclosure dipilih sebagai strategi untuk mencapai tujuan tersebut, dan siapa target juga harus dipilih. Tahap selanjutnya individu mengevaluasi manfaat dan risiko subyektif dari keterbukaan diri yang akan dilakukan. Jika dirasa bermanfaat maka individu akan memperluas dan memperpanjang durasi self disclosure namun jika dirasakan berisiko maka akan menentukan kedalaman informasi yang diungkap.

Devito (2018) mengungkapkan bahwa self disclosure diartikan sebagai informasi yang sebelumnya tidak diketahui oleh penerima dan mungkin berbeda dari biasanya. Sependapat dengan yang diungkapkan Widyarini (2009) bahwa melakukan pengungkapan diri dapat berpengaruh positif terhadap kesehatan fisik dan emosi. Teori ini banyak dipakai karena sejalan dengan tujuan fungsional pembukaan diri itu sendiri yaitu: ekspresi diri, klarifikasi diri, validasi sosial, membangun hubungan, dan kontrol sosial (Omarzu, 2000). Berdasarkan uraian tersebut maka dapat disimpulkan bahwa self disclosure dapat memengaruhi resiliensi individu. Hal ini kemudian menjadi dasar rumusan "Peran Self Disclosure dengan Resiliensi pada Remaja di Panti Asuhan".

\section{METODE}

Penelitian ini dilakukan dengan mix method, dimana metode kuantitatif dan kualitatif 
(Siswanto, Susila \& Suyanto 2017). Pengumpulan data dilakukan dengan pemberiaan skala, wawancara dan observasi. Subjek dalam penelitian ini berjumlah 90 remaja di Panti Asuhan RAHPIA Medan. Teknik pengambilan sampel yang digunakan dalam penelitian ini adalah total sampling atau sampling jenuh.

Data dikumpulkan dengan menggunakan dua skala yaitu skala self disclosure dan skala resiliensi. Skala self disclosure terdiri dari 44 aitem berdasarkan teori Devito (2018) yaitu amount, valence, accuracy / honesty, intention, dan intimacy dengan contoh aitem sebagai berikut: 1) saya menceritakan kepada teman tentang keinginan saya agar mereka dapat memahami saya, 2) saya merasa kurang nyaman apabila orang lain ingin mengetahui permasalahan yang saya alami, 3) saya selalu menceritakan pengalaman yang baru saya alami kepada teman. Skala self disclosure memiliki a 0,966 dengan r 0,314-0,687. Sedangkan untuk skala resiliensi dikemukakan oleh Reivich dan Shatte (dalam Nasution, 2011) yaitu regulasi emosi, impuls control, optimisme, causal analysis, empati, self efficacy dan reaching out dengan contoh aitem sebagai berikut: 1) saya berusaha tenang agar dapat menyelamatkan diri dari suatu masalah, 2) saya yakin bahwa setiap masalah pasti ada solusinya, 3) saya membantu orang yang mengalami masalah karena saya ikut sedih jika orang lain menderita. Skala self efficacy memiliki $\alpha 0,920$ dengan $r$ bergerak dari 0.307 hingga 0.819 .

HASIL

Tabel 1.

Karakteristik Subjek

\begin{tabular}{lcc}
\hline Gender & Jumlah & Persentase (\%) \\
\hline Laki-laki & 58 & 64,4 \\
\hline Perempuan & 32 & 35,6 \\
\hline Total & 90 & 100
\end{tabular}

Tabel 2.

Data Deskriptif Resiliensi dan Self Disclosure

\begin{tabular}{lcc}
\hline & Resiliensi & Self Disclosure \\
\hline Skor Minimum & 134 & 100 \\
\hline Skor Maksimum & 192 & 140 \\
\hline Skor Rata-rata & 159,5 & 122,7 \\
\hline Standar Deviasi & 12,15 & 6,98 \\
\hline Kategori Rendah (Persentase) & 0 & 0 \\
\hline Kategori Sedang (Persentase) & $85(94,4 \%)$ & $72(80 \%)$ \\
\hline Kategori Tinggi (Persentase) & $5(5,6 \%)$ & $18(20 \%)$ \\
\hline
\end{tabular}

Berdasarkan data pada tabel 2, hasil penelitian di atas menunjukkan bahwa hasil deskripsi keseluruhan subjek penelitian adalah dari 90 subjek, terdapat 85 subjek $(94,4$ persen) memiliki resiliensi sedang, dan terdapat 5 subjek (5,6 persen) memiliki resiliensi tinggi. Selanjutnya pada tingkat self disclosure, terdapat 72 subjek (80 persen) memiliki self disclosure sedang, dan terdapat 18 subjek (20 persen) yang memiliki self disclosure tinggi. 
Tabel 3.

Penjabaran Model Regresi dari Variabel Penelitian

\begin{tabular}{ccccc}
\hline Analisis & Pearson Product Moment & Sig & $\boldsymbol{R}$ Square & Keterangan \\
\hline Koefisien & 0,678 & 0,00 & 0,460 & signifikan \\
\hline
\end{tabular}

Melalui tabel 3, diketahui hasil perhitungan uji hipotesis bahwa terdapat hubungan positif dan signifikan, dengan $\mathrm{R}^{2}$ sebesar 0.460 . Berdasarkan hasil tersebut, dapat disimpulkan bahwa sumbangan efektif self disclosure terhadap resiliensi sebesar $46 \%$.

\section{PEMBAHASAN}

Penelitian ini menunjukkan terdapat hubungan positif antara self disclosure dengan resiliensi pada remaja yang tinggal di Panti Asuhan RAHPIA Medan. Sejalan dengan penelitian yang dilakukan oleh Rahmawati dan Dewinda (2015) terhadap 40 remaja di panti asuhan, menyatakan bahwa terdapat hubungan yang positif dan signifikan antara self disclosure dengan resiliensi. Hal ini juga diperkuat dengan riset yang dilakukan oleh Ko dan $\mathrm{Pu}$ (2011) menyatakan bahwa terhadap hubungan yang positif dan signifikan antara self disclosure dengan resiliensi.

Bacchi dan Licinio (2017), dalam penelitiannya menunjukkan bahwa remaja panti asuhan lebih rentan mengalami depresi, biasanya kebutuhannya secara fisik dan emosional tidak diperoleh dari orangtua. Dengan kata lain, resiliensi di perlukan untuk membantu individu menghadapi tekanan dan masalah (Utami \& Helmi, 2017), namun kerentanan terhadap depresi pada remaja di panti asuhan (Bacchi \& Licinio, 2017) membuat individu cenderung mengalami kesulitan resiliensi di banding individu dengan keluarga lengkap.

Resiliensi dapat dilakukan dengan menunjukkan kepercayaan terhadap kemampuan diri. Menurut Devito (2018), salah satu tanda kepercayaan dan afeksi yang ditunjukkan seseorang adalah dengan melakukan self disclosure. Dalam menjelaskan hubungan self disclosure dengan resiliensi Boyd dan Ellison (2007) mengungkapkan self disclosure di anggap salah satu tipe komunikasi dimana informasi diri sendiri (self) yang biasanya disembunyikan dari orang lain kini dikomunikasikan kepada orang lain atau sekelompok organisasi, karena keterbukaan diri dalam sosial bermasyarakat bermanfaat untuk menjadi sarana dalam mempresentasikan identitas diri dan akan memiliki resiliensi dalam diri individu tersebut. Devito (2017) mengungkapkan bahwa self disclosure atau pengungkapan diri yang merupakan jenis komunikasi dimana kita mengungkapkan informasi tentang diri individu sendiri yang secara aktif disembunyikan.

Berdasarkan hasil penelitian, diperoleh data yaitu sebanyak 85 remaja di Panti Asuhan Rahpia Medan dengan presentase 94,4 persen termasuk ke dalam kategori resiliensi sedang. Penelitian yang dilakukan terhadap remaja di panti asuhan menunjukkan bahwa para subjek berusaha untuk tetap bertahan dan menghadapi permasalahannya dengan melakukan hal-hal positif, seperti bermain musik ketika sedang kesal. Remaja lebih memilih berusaha tenang agar dapat menyelamatkan diri dari suatu masalah. Hal ini merupakan salah satu perwujudan dari aspek resiliensi yaitu regulasi emosi.

Beberapa subjek yang tidak memiliki kesulitan dalam urusan konfik, tapi masih ada subjek yang kurang mampu dalam menyelesaikan masalah. Sebagai langkah mengatasi hal ini bimbingan yang diberikan oleh pengurus panti kepada beberapa remaja di Panti Asuhan 
RAHPIA Medan, dengan tujuan bahwa remaja yang tinggal di panti asuhan dapat memiliki dan mampu kemampuan menyelesaikan masalah dengan baik, memahami bagaimana proses-proses untuk mencari jalan keluar dalam pemecahan masalah. Dalam menyelesaikan masalah, diperlukan langkah-langkah yang dimulai dari mencari dan memahami suatu permasalahan yang ada, menyusun strategi menyelesaikan masalah, mencari wawasan lebih luas untuk mendapatkan suatu solusi penyelesaian masalah, serta memikirkan dan mengartikan kembali solusi penyelesaian masalah tersebut. Aspek empati juga didapat kuat pada subjek yang berada pada kategori sedang. Hasil wawancara yang peneliti lakukan menggambarkan para subjek dapat memahami teman mereka yang sangat terpukul dengan masalah yang sedang dialami.

Sisanya sebanyak 5 subjek atau 5,6 persen remaja yang berada di Panti Asuhan RAHPIA Medan menunjukkan tingkat resiliensi pada kategori tinggi. Hasil observasi menunjukkan bahwa subjek memiliki kemampuan memahami kondisi seseorang dari cara mereka bersikap. Subjek menyelesaikan setiap masalah dengan kepala dingin. Beberapa subjek menjelaskan dapat mengendalikan diri dengan baik, namun sebagian kecil menyatakan lebih memilih menghindar pada saat menemui suatu masalah. Hasil wawancara yang peneliti lakukan menggambarkan bahwa subjek yakin kegagalan yang mereka alami dikarenakan kurangnya usaha diri sendiri. Beberapa remaja lainnya menyatakan ketika masalah muncul, mereka mampu mencari jalan keluar atas permasalahan, namun ada juga beberapa anak panti yang ragu dapat menyelesaikan masalah yang hadapi.

Rata-rata remaja di panti asuhan memiliki rasa kepedulian yang tinggi dengan sesamanya, memiliki rasa ingin tahu dan ingin mencoba hal-hal baru, serta mampu untuk menjalin hubungan dengan orang-orang baru dalam lingkungan kehidupan. Subjek mampu menginterpretasikan masalah yang dihadapinya. Interpretasi tersebut merupakan faktor penting dalam memprediksikan level resiliensi individu dalam menghadapi kesulitan, sebab bagaimana individu memilih menginterpretasikan kesulitan yang dihadapinya akan membentuk pola pandang keseluruhan individu, baik dalam kehidupan secara umum maupun spesifik yang berhubungan dengan kesulitan yang dihadapi. Temuan ini sejalan dengan Nasution (2011) bahwa individu dengan kemampuan resiliensi yang baik harus memenuhi aspek cause analysis, dalam artian bahwa individu mampu menginterpretasi penyebab terjadinya masalah sehingga mampu bertahan mengahadapi masalah. Resiliensi memberi kemampuan untuk bangkit kembali dari hal yang tidak menyenangkan. Individu akan mengubah kapasitas resiliensi menjadi sebuah kekuatan untuk menghadapi masalah dalam diri individu. Mereka tidak mampu menjaga keseimbangan dalam menghadapi tekanan yang kuat (Utami \& Helmi, 2017).

Berdasarkan hasil observasi dan wawancara terhadap remaja di panti asuhan menunjukkan self disclosure yang sedang dengan presentase 80 persen terlihat dari aspek valence dan accuracy/honesty. Hal ini sejalan dengan hasil observasi dengan beberapa remaja menunjukkan bagaimana individu mampu menceritakan pada teman tentang hal-hal dan keinginan yang sedang mereka rasakan. Sebanyak 18 subjek (20 persen) remaja yang berada di Panti Asuhan RAHPIA Medan memiliki self disclosure tinggi. Peneliti menemukan bahwa para remaja mengaku memiliki rasa nyaman membuat mereka akan berkomunikasi dengan siapa saja. Hal ini membuat para subjek merasa self disclosure itu perlu diterapkan pada diri sendiri dan antar sesama. Meskipun beberapa para subjek merasa kesulitan apabila mengungkapkan pendapat di depan orang-orang yang baru kenal, hal tersebut tidak mengurangi sikap self disclosure yang dimiliki subjek tersebut. Individu berpendapat, bahwa nilai dari self disclosure dilihat dengan tidak pernah menceritakan kekesalan pada orang lain. Pada aspek amount mengenai selalu 
menceritakan kepada teman mereka mengenai kegiatan keseharian, atau terbiasa berbicara di depan banyak orang. Hasil wawancara menggambarkan remaja di panti asuhan sering mengungkapkan atau terbiasa berbagi cerita dengan teman mereka. Individu mengaku selalu menceritakan kejadian-kejadian yang menyenangkan kepada teman. Remaja di panti asuhan melihat keadaan dan memilih kata-kata yang tepat untuk mengungkapkan apa yang mereka pikirkan. Kuantitas dari pengungkapan diri dapat diukur dengan mengetahui frekuensi dengan siapa individu mengungkapkan diri dan durasi dari pesan self disclosure atau waktu yang diperlukan untuk mengutarakan statement self disclosure individu tersebut terhadap orang lain.

Temuan ini sejalan Hargie dan Dickson (2004) self disclosure adalah suatu pernyataan secara individu tentang diri mereka termasuk pikiran, perasaan dan pengalaman kepada orang lain. Sears, Freedman, dan Peplau (dalam Dayakisni \& Hudaniah, 2009) mengatakan bahwa pada umumnya ketika berhubungan dengan orang asing, self disclosure kurang mendalam dan rentangnya sempit, sedangkan perkenalan biasa, self disclosure lebih dalam dan rentangnya luas, sementara hubungan dengan teman dekat ditandai dengan adanya self disclosure yang mendalam dan rentanya terluas.

Berdasarkan penjelasan diatas maka dapat dikatakan bahwa internalisasi pengungkapan perasaan dan informasi yang kemudian diwujudkan dalam tingkah laku sehari-hari dapat membantu remaja di panti asuhan agar mampu mengatasi permasalahan yang sedang dialami. Secara umum informasi yang intens secara emosional, negatif atau memalukan cenderung dinilai lebih tinggi dalam keintiman. Kedalaman diukur baik menggunakan instrumen laporan diri atau dengan menilai pengungkapan aktual yang dibuat untuk tingkat keintiman pada saat self disclosure terhadap resiliensi remaja panti asuhan dalam penelitian ini.

\section{KESIMPULAN}

Berdasarkan hasil penelitian, maka dapat diambil kesimpulan bahwa self disclosure dan resiliensi memiliki hubungan yang positif dan signifikan. Penelitian ini menjelaskan bahwa self disclosure yang dimiliki dapat memengaruhi tingkat resiliensi dan merupakan faktor penting terhadap munculnya resiliensi dalam diri individu.

\section{DAFTAR PUSTAKA}

Apelian, E., \& Nesteruk, O. (2017). Reflections of Young Adults on the Loss of a Parent in Adolescence. International Journal of Child, Youth and Family Studies, 8(3/4), 79. https://doi.org/10.18357/ijcyfs83/4201718002

Bacchi, S., \& Licinio, J. (2017). Resilience and Psychological Distress in Psychology and Medical Students. Academic Psychiatry, 41(2), 185-188. https://doi.org/10.1007/s40596016-0488-0

Boyd, D. M., \& Ellison, N. B. (2007). Social network sites: Definition, history, and scholarship. Journal of Computer-Mediated Communication, 13(1), 210-230. https://doi.org/10.1111/j.1083-6101.2007.00393.x

Dayakisni, T., \& Hudaniah. (2009). Psikologi Sosial. Medan: USU Press.

Desmita. (2008). Psikologi Perkembangan. Bandung: PT Rosda.

Devito, J. A. (2018). The Interpersonal Communication Book (13th Editi). New York: Pearson Education Inc. 
Hargie, O., \& Dickson, D. (2004). Skilled Interpersonal Communication: Research, Theory and Practice (Fourth Edi). London And New York: Routledge Taylor \& Francis Group.

Irshad, M. (2017). Psikologi Remaja: Perkembangan Peserta Didik (Edisi Keen). Jakarta: Bumi Aksara.

Ko, H. C., \& Pu, H. J. (2011). Understanding the impact of bloggers' self-disclosure on resilience. Proceedings of the 5th International Conference on Ubiquitous Information Management and Communication, 2011. https://doi.org/10.1145/1968613.1968663

Nasution, S. . (2011). Daya Pegas Menghadapi Trauma Kehidupan (USU Press). Medan.

Nisa, M. K., \& Muis, T. (2016). Studi Tentang Daya Tangguh ( Resiliensi ) Anak Di Panti Asuhan Sidoarjo A Study Of Children Resilience In Sidoarjo Orphanages. Jurnal Mahasiswa Unesa, (resiliensi), 40-44.

Omarzu, J. (2000). A disclosure decision model: Determining how and when individuals will self-disclose. Personality and Social Psychology Review, 4(2), 174-185. https://doi.org/10.1207/S15327957PSPR0402_05

Pidgeon, A. M., Rowe, N. F., Stapleton, P., Magyar, H. B., \& Lo, B. C. Y. (2014). Examining Characteristics of Resilience among University Students: An International Study. Open Journal of Social Sciences, 02(11), 14-22. https://doi.org/10.4236/jss.2014.211003

Rahmawati, \& Dewinda, H. R. (2015). Hubungan antara Self Disclosure dengan Resiliensi pada Remaja di Panti Asuhan Putra Bangsa Yayasan Budi Mulia Padang. Jurnal PSYCHE, 8(2), $11-22$

Ungar, M. (2008). Resilience across cultures. British Journal of Social Work, 38(2), 218-235. https://doi.org/10.1093/bjsw/bcl343

Utami, C. T., \& Helmi, A. F. (2017). Self-Efficacy dan Resiliensi: Sebuah Tinjauan MetaAnalisis. Buletin Psikologi, 25(1), 54-65. https://doi.org/10.22146/buletinpsikologi.18419

Widyarini, N. (2009). Seri Psikologi Populer : Kunci Pengembangan Diri. Jakarta: PT. Alex Media Komputindo. 